Brazilian Journal

of Chemical

\title{
MODELLING ION TRANSPORT IN AN AMINE SOLUTION THROUGH A NANOFILTRATION MEMBRANE
}

\author{
Asma Ghorbani ${ }^{1}$, Behrouz Bayati ${ }^{1 *}$ and Tavan Kikhavani ${ }^{1}$ \\ ${ }^{1}$ Ilam University, Department of Chemical Engineering, Ilam, Iran. ORCID: 0000-0003-2686-802X; E-mail: b.bayati@ilam.ac.ir - \\ ORCID: 0000-0002-4239-9828; ORCID: 0000-0002-2764-5103
}

(Submitted: February 8, 2019 ; Revised: May 12, 2019 ; Accepted: June 6, 2019)

\begin{abstract}
The performance of a flat sheet polyamide nanofiltration membrane in rejection of a binary mixture of heat stable salts (acetate and sulfate) from methyl-diethanolamine (MDEA) solution was investigated. The effects of pressure and concentration of MDEA solution on rejection of acetate and sulfate ions were studied. At MDEA concentration of $20 \%$ wt. and pressure of 70 bar, $80 \%$ and $98 \%$ rejection can be obtained for acetate and sulfate ions, respectively. Membrane performance and transport coefficients were investigated using the Spiegler-Kedem-Katchalsky (SKK) model, film theory and extended Nernst-Planck (FT-ENP) model. The results of the FT-ENP model show accurate agreement with experimental results. This result can be obtained due to considering the charge repulsion of sulfate ions. For sulfate ions, both models show errors less than $1 \%$ with $>R^{2}=0.98$. In the case of acetate, errors less than $3 \%\left(>R^{2}=0.75\right)$ and $2 \%\left(>R^{2}=0.89\right)$ were obtained for the SKK and FT-ENP models, respectively.

Keywords: Amine solution; Nanofiltration membrane; Spiegler-Kedem-Katchalsky model; Film theory; NernstPlanck equation.
\end{abstract}

\section{INTRODUCTION}

Natural gas often contains impurities such as hydrogen sulfide $\left(\mathrm{H}_{2} \mathrm{~S}\right)$ and carbon dioxide $\left(\mathrm{CO}_{2}\right)$ that are toxic and cause corrosion in the equipment and environmental pollution during burning. Thus, these impurities must be removed from the gas to reduce the harmful effects. Alkanol amine solutions including methyl-diethanolamine (MDEA), monoethanolamine (MEA), piperazine (PZ), diethanolamine (DEA) and diisopropanolamine (DIPA) are used in sweetening natural gas and removing impurities (Jaafari et al., 2018; Lu et al., 2017; Najibi and Maleki, 2013; Poormohammadian et al., 2015; Qeshta et al., 2015; Qiu et al., 2014; Rebolledo-Libreros and Trejo, 2004; Santaniello and Golemme, 2018). MDEA is usually used in the concentration range of 40 to $50 \%$ for the removal of acid gases in the gas sweetening unit (Keewan et al., 2018; Pal et al., 2015). The reaction between MDEA and hydrogen sulfide leads to the production of $\mathrm{MDEAH}^{+}$ions and anions such as acetate, nitrate, formate, glycolate, chloride, and sulfate, etc. The reaction between these anions and $\mathrm{MDEAH}^{+}$forms a stable salt (HSS) that cannot be regenerated through heating (Meng et al., 2008; Pal et al., 2013). The presence of these salts in amines leads to operational problems such as corrosion, fouling, foaming, high viscosity, and capacity reduction (Cho et al., 2015; Pal et al., 2014; Verma and Verma, 2009; Wang et al., 2015). Therefore, the removal of HSS ions from the amine solution is very important. Various technologies can be used to remove stable salts, including ion exchange, distillation and electrodialysis (ED) (Bazhenov et al., 2015; Cho et al., 2015; Dumée et al., 2012; Gao et al., 2015). Another effective method for the removal of HSS ions is the nanofiltration (NF) membrane process that is rarely studied. Distillation has high-energy consumption,

\footnotetext{
* Corresponding author: Behrouz Bayati - E-mail: b.bayati@ilam.ac.ir
} 
low amine recovery and high probability for thermal degradation. The ion exchange technique is suitable for low salts concentrations. Resin fouling, thermal degradation, permanent poisoning and high rate of resin consumption can be mentioned as disadvantages of this technique. ED has more power consumption and waste products than ion exchange and vacuum distillation, respectively. Furthermore, selective membranes with high chemical stability should be used in ED (Dumée et al., 2012).

$\mathrm{NF}$ is a pressure-driven membrane process that has characteristics between ultrafiltration (UF) and reverse osmosis (RO) (Roy et al., 2017; Ryzhkov and Minakov, 2016; Wei et al., 2016; Zhao et al., 2016). NF has important advantages including lower pressure, higher permeate flux, low rejection for monovalent ions, high rejection for multivalent ions, and low energy consumption (Wei et al., 2016). The rejection of ions in NF is mainly based on the size (steric), the charge (Donnan exclusion) mechanisms and dielectric exclusion (Epsztein et al., 2018; Fridman-Bishop et al., 2018; Saliha et al., 2009; Santafé-Moros et al., 2005; Wei et al., 2018). The removal of HSSs from amine solutions was studied by .Lim et al. (2014). However, the results were not extended. They used NF to concentrate HSSs in MEA solution and found that $80 \%$ of HSS ions with amine rejection less than $7 \%$ can be removed using NF.

Investigation of the transport mechanisms of ions through membranes provides a better understanding of membrane performance in ion removal. Therefore, the study of HSS ion transport parameters in the amine solution by the NF membrane can be helpful in better understanding the NF membrane performance and rejection mechanism that has not been addressed in the literature. The transport mechanisms of ions in water through the NF membrane have been studied. $\mathrm{Hu}$ and Dickson (2006) investigated the performance of the NF membrane for fluoride removal from water using constant surface electrical potential $(\psi)$, pore radius $\left(\mathrm{r}_{\mathrm{p}}\right)$ and pure water permeability $\left(\mathrm{L}_{\mathrm{p}}\right)$ parameters. They estimated the membrane parameters by the extended Nernst-Planck equation and the Grahame equation and observed a good agreement between model and experimental data. The effect of the concentration on the rejection of ions and transport parameters $\left(\mathrm{K}_{\mathrm{eff}}\right.$ and $\Phi)$ was investigated by Garba et al. (2003). They found that the transport parameters increase with increasing concentration and the model presented a satisfactory agreement with experimental results. Predicting the rejection of ions by the pore transport model was investigated by Déon et al. (2012). They found that the proposed model showed a good estimate of ion rejection by Pérez et al. (2017) evaluated the differences in rejection of salt by the solutiondiffusion-film model (SDFM). They observed a good agreement between model and experimental data. Therefore, the SDFM model could be useful for evaluating the NF membrane performance. Fang and Deng (2014) investigated the effects of operating pressure, $\mathrm{pH}$, arsenate initial concentration, ionic strength on the membrane performance. They studied the transport mechanism by concentration polarization film theory and the Donnan Steric Pore Models. Their results showed that electro-migration and convection transport dominated at high flux and diffusive transport dominated at low flux.

The investigation of hydrothermal stability and the effect of permeation temperature on the transport mechanism of neutral solutes and water through TiO2ZrO2 (5/5) NF membranes, based on the SpieglerKedem model were carried out by Anisah et al. (2019). They realized that the permeation properties of neutral solutes and water according to the Spiegler-Kedem analysis were activated processes. Zhang et al. (2019) developed a model to investigate the concentration polarization and separation performance of a NF system. The transport phenomena in NF channels and permeation properties through NF membranes were evaluated using computational fluid dynamics (CFD) and SKK model, respectively. Their model is useful for predicting the concentration polarization in NF and RO membrane systems and modeling of the solute transport. Performance of RO membranes for rejection of $\mathrm{Cr}(\mathrm{VI})$ and fluoride ions was investigated by the combined equations of film theory-Spiegler-Kedem (CFSK) and film theory-solution-diffusion (CFSD) models by Gaikwad and Balomajumder (2017b). They found that there was good agreement between results of the CFSK model and experimental results. In other work, Gaikwad and Balomajumder (2017c) used the NF500 nanofiltration membrane for separation of fluoride and $\mathrm{Cr}$ (VI). They evaluated the mass transfer coefficient and membrane transport parameters using the CFSK model. Their model show good correlations with experimental results.

In the literature, only parameters and mechanisms of ion transport in water solutions have been investigated, while HSS ions are present in aqueous amine solutions. Thus, the evaluation of ion transport parameters in the presence of amine is of particular importance. Therefore, in this study, the effects of operating pressure and amine concentration on permeate flux and HSS ions rejection through a NF-3 membrane for the binary mixture of acetate and sulfate were studied. Rejections of sulfate and acetate ions were predicted by the transport coefficients of the salt permeability $\left(\mathrm{P}_{\mathrm{S}}\right)$, reflection coefficient $(\sigma)$ and solvent permeability $\left(\mathrm{L}_{\mathrm{p}}\right)$ using the Spiegler-KedemKatchalsky model. Besides, the transport parameters including the salt transmittance $(\Phi)$ and the effective salt transfer coefficient $\left(\mathrm{K}_{\text {eff }}\right)$ were estimated by the 
proposed model of the film theory and the extended Nernst-Planck equation. Then the ion rejection rate was calculated by the models and compared to the experimental results.

\section{THEORETICAL BACKGROUND}

The transport of ions through membrane pores can be explained by the Spiegler-Kedem-Katchalsky model that is based on non-reversible thermodynamics. This model considered the membrane as a black box, without any characterization of the electrical and structural properties of the membrane. The basic transport equations provided by the SKK model are given as follows (Diawara et al., 2003; Hidalgo et al., 2013; Kelewou et al., 2011; Marchetti et al., 2014; Wu et al., 2015):

$\mathrm{J}_{\mathrm{V}}=\mathrm{L}_{\mathrm{P}}(\Delta \mathrm{P}-\sigma \Delta \pi)$

$\mathrm{J}_{\mathrm{S}}=\mathrm{P}_{\mathrm{S}} \cdot\left(\mathrm{C}_{\mathrm{m}}-\mathrm{C}_{\mathrm{P}}\right)+(1-\sigma) \cdot \mathrm{J}_{\mathrm{V}} \cdot \mathrm{C}_{\mathrm{S}}$

where $\mathrm{J}_{\mathrm{V}}$ and $\mathrm{J}_{\mathrm{S}}$ are solvent and solute flux, respectively. $\mathrm{C}_{\mathrm{m}}, \mathrm{C}_{\mathrm{p}}$, and $\mathrm{C}_{\mathrm{S}}$ are respectively the concentrations of solute on the membrane surface, in the permeate, and in the solution; $\Delta \mathrm{P}$ and $\Delta \pi$ are respectively the pressure difference and osmotic pressure difference; $\mathrm{L}_{\mathrm{P}}$ is the solvent permeability; $\mathrm{P}_{\mathrm{S}}$ is the permeability of solute; $\sigma$ is the reflection coefficient. In the SKK model: 1) the charge of solute and membrane are not considered. 2) The driving force included the pressure and concentration gradient. 3) Solute in solution is semipermeable for the membrane. 4) $\sigma, \mathrm{P}_{\mathrm{S}}$ and $\mathrm{L}_{\mathrm{p}}$ are constants across the membranes. $\sigma$ is the rejection capability of the membrane, which for no rejection and rejection of $100 \%$ are 0 and 1 , respectively.

The observed rejection can be expressed by SKK theory as follows (Diawara et al., 2003; Hidalgo et al., 2013; Kelewou et al., 2011; Marchetti et al., 2014; Wu et al., 2015):

$\mathrm{R}_{\mathrm{O}}=\frac{\sigma(1-\mathrm{F})}{\mathrm{F} \cdot(1-\sigma)}$

$\mathrm{F}=\exp \left(-\frac{1-\sigma}{\mathrm{P}_{\mathrm{S}}} \cdot \mathrm{J}_{\mathrm{V}}\right)$

where $R_{O}$ is the observed rejection and $J_{V}$ is the solvent flux obtained from the experimental results. The simple forms of Eqs. (3) and (4) are given as follow (Diawara et al., 2003; Hidalgo et al., 2013; Kelewou et al., 2011; Marchetti et al., 2014; Wu et al., 2015):

$\mathrm{R}_{\mathrm{O}}=\mathrm{a} \cdot\left(1-\exp \left(-\mathrm{b} \cdot \mathrm{J}_{\mathrm{V}}\right)\right)$ where $\mathrm{a}=\sigma / 1-\sigma$ and $\mathrm{b}=1-\sigma / \mathrm{P}_{\mathrm{s}}$. The $\sigma$ and $\mathrm{P}_{\mathrm{s}}$ parameters can be simultaneously estimated using a numerical method from the experimental data of $R_{O}$ versus $\mathrm{J}_{\mathrm{v}^{*}}$

\section{EXPERIMENTAL}

\section{Materials}

The NF membrane used in this study was a commercial NF-3 membrane that was prepared by Sepro Co., USA. According to the manufacturer specifications, the NF-3 polymeric membrane has three layers including a polyamide surface layer and polyester support with a polysulfone substrate. The molecular weight cut-off (MWCO) $(\mathrm{g} / \mathrm{mol})$ and the pore size of the membrane are 250-300 and $0.55 \mathrm{~nm}$, respectively. Also, the operating conditions and water flux for NF-3 are $50{ }^{\circ} \mathrm{C}, 83$ bar, $\mathrm{pH} 3-10$ and $42 \mathrm{~L} /$ $\mathrm{m}^{2} \mathrm{~h}$, respectively. According to the negative charge of HSS ions, the $\mathrm{pH}$ of the amine solution and the size of MDEA molecules (119.163 gr/mol), NF-3 membrane with negative charge, high chemical resistance and suitable pore size was chosen as an appropriate membrane for separation of HSS ions.

Sodium acetate $\left(\mathrm{C}_{2} \mathrm{H}_{3} \mathrm{NaO}_{2}\right)$ and sodium sulfate $\left(\mathrm{Na}_{2} \mathrm{SO}_{4}\right)$ were purchased from Ghatran Shimi tajhiz, Iran. Methyl-diethanolamine $\left(\mathrm{C}_{5} \mathrm{H}_{13} \mathrm{O}_{2} \mathrm{~N}\right)$ was obtained from the Ilam Gas Treating Company.

\section{Experimental method}

The removal of HSS from the amine solution was performed with a flat sheet NF membrane using cross flow filtration. It is a circular batch process, in which permeate and retentate flows were returned to the feed solution to maintain the concentration and volume constant during the NF experiment. The schematic of the NF set-up is shown in Fig. 1. The effective area of the NF membrane was approximately $0.0113 \mathrm{~m}^{2}$. The membrane was soaked in distilled water for 24 $\mathrm{h}$ before use. The applied pressure was in the range of 50-80 bar. The recovery ratio and feed flow rate were kept at 0.45 and $0.693 \mathrm{~L} / \mathrm{h}$, respectively, for all tests. The temperature of all tests was fixed at $35{ }^{\circ} \mathrm{C}$. The feed temperature was controlled by cold

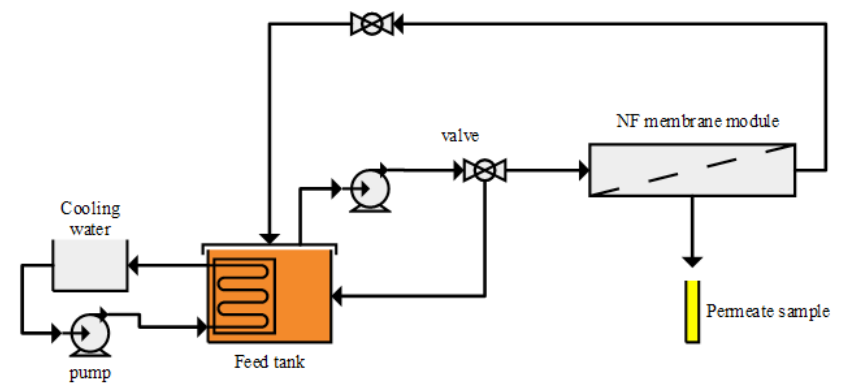

Figure 1. Schematic diagram of the nanofiltration setup. 
water circulation. Before each test, the membrane was washed with distilled water at 20 bar. After obtaining stable conditions, permeate samples were collected. The $\mathrm{pH}$ of the feed solution was about 10 . Feed solutions contained different concentrations of methyl-diethanolamine (20-45 wt. \%) and binary ionic mixtures. The properties and concentration of ions are given in Table 1.

The rejection of ions $\left(\mathrm{R}_{\mathrm{O}}\right)$ and permeate flux $\left(\mathrm{J}_{\mathrm{V}}\right)$ were calculated to investigate the performance of the membrane by the following equations (Zhao et al., 2013):

$\mathrm{R}_{\mathrm{O}}(\%)=\left(1-\frac{\mathrm{C}_{\mathrm{P}}}{\mathrm{C}_{\mathrm{F}}}\right) \times 100$

$\mathrm{J}_{\mathrm{V}}=\frac{\mathrm{V}}{\text { A.t }}$

where $\mathrm{C}_{\mathrm{F}}, \mathrm{C}_{\mathrm{P}}, \mathrm{V}(\mathrm{l}), \mathrm{A}\left(\mathrm{m}^{2}\right)$ and $\mathrm{t}(\mathrm{h})$ denote the feed concentration, permeate concentration, permeate volume, effective membrane area and time, respectively. The concentrations of ions in the permeate samples were measured using an ion chromatography instrument (I.C., metrosep a SUPP 5-250).

Table 1. Properties and concentration of ions in feed solution.

\begin{tabular}{ccccc}
\hline Ions & $\begin{array}{c}\text { MW. } \\
(\mathbf{g} / \mathbf{m o l})\end{array}$ & $\begin{array}{c}\text { hydration } \\
\text { radius } \\
(\mathbf{n m}) *\end{array}$ & $\begin{array}{c}\text { Energy } \\
\text { hydration * } \\
(\mathbf{k J} / \mathbf{m o l})\end{array}$ & $\begin{array}{c}\text { Feed } \\
\text { concentration } \\
(\mathbf{m g} / \mathbf{L})\end{array}$ \\
\hline $\mathrm{C}_{2} \mathrm{H}_{3} \mathrm{O}_{2}{ }^{-}$ & 59.04 & 0.260 & 328.936 & 300 \\
$\mathrm{SO}^{2-}$ & 96.06 & 0.306 & 1072.84 & 150 \\
\hline${ }^{2}$
\end{tabular}

\section{Membrane characterization}

The surface zeta potential of the NF-3 membrane was specified through streaming potential measurements with the SurPASS electrokinetic analyzer (Anton Paar, Austria). The streaming potential was carried out using $1 \mathrm{mM}$ aqueous $\mathrm{KCl}$ solutions at $25.0{ }^{\circ} \mathrm{C}$ and $\mathrm{pH}$ ranging from 2.5 to 10.2 . $\mathrm{pH}$ was adjusted by titration of the $\mathrm{KCl}$ solution with $0.1 \mathrm{M} \mathrm{NaOH}$ and $\mathrm{HCl}$. Then, the surface charge and the isoelectric point of the NF-3 membrane were specified.

\section{RESULT AND DISCUSSION.}

\section{Membrane characterization}

The zeta potential as a function of $\mathrm{pH}$ for the NF-3 membrane is presented in Table 2 . It is evident that the isoelectric point of the NF-3 membrane is at $\mathrm{pH} 5.06$, which indicates the negative surface charge of the NF-3 membrane at $\mathrm{pH} 7$. On the other hand, the zeta potential of NF-3 increased from $31.6 \mathrm{mV}$ to $-73.3 \mathrm{mV}$ upon increasing the $\mathrm{pH}$ from 2.5 to 10.2 . Therefore, the NF-3 membrane has an extremely negative surface charge at a higher $\mathrm{pH}$.

\section{Effect of applied pressure and MDEA concentration}

The removal of HSS from amine aqueous solutions is important due to its destructive effects and reduction of solvent capacity in the process of sour gas sweetening. Therefore, it is important to provide comprehensive information on the performance of the NF process, which can be an optimal way for the purification of circulating amine. In this way, the effects of pressure on permeate flux and rejection of ions in the $\mathrm{C}_{2} \mathrm{H}_{3} \mathrm{O}_{2}{ }^{-} / \mathrm{SO}_{4}{ }^{-2}$ binary mixture from $20-45$ wt. \% of MDEA solutions were investigated for the NF membrane. As can be seen in Fig. 2, permeate flux increased with increasing pressure for all of the MDEA concentrations. The enhancement of permeate flux is due to the increased driving force and overcoming the membrane resistance, as expressed in Eq. (1).

As shown in Fig. 2, an increase of the concentration of MDEA in the solution leads to a reduction of permeate flux. Permeate flux increased from 35.5 to $83.84 \mathrm{~L} / \mathrm{h} . \mathrm{m}^{2}$ with increasing pressure from 40 to 70 bar for $20 \mathrm{wt}$ \% MDEA, while for $45 \mathrm{wt} \%$ MDEA the permeate flux increased from 13.64 to $31.32 \mathrm{~L} / \mathrm{h} . \mathrm{m}^{2}$ with increasing pressure. This can be due to increased osmotic pressure with increasing amine concentration according to the Van't Hoff equation. The Van't Hoff equation is (Nakari et al., 2016):

$\pi=\mathrm{CRT}$

In this equation, $\pi$ is osmotic pressure $(\mathrm{kPa}), \mathrm{C}$ is the concentration of MDEA in solution ( $\mathrm{mol} / \mathrm{L}), \mathrm{R}$ is the gas constant $(8.314 \mathrm{kPa} . \mathrm{L} / \mathrm{K} . \mathrm{mol})$, and $\mathrm{T}$ is the temperature $(\mathrm{K})$. In this work, the osmotic pressure of ions is negligible due to the higher concentration of amine and ions. Therefore, the osmotic pressure in this study is the osmotic pressure of the amine solution. Osmotic pressure data are reported for various concentrations of MDEA at $35{ }^{\circ} \mathrm{C}$ in Fig. 3. Therefore, increasing concentrations of MDEA result in increasing osmotic pressure and lead to a reduction in permeate flux (Eq. (8)).

The rejection of the $\mathrm{C}_{2} \mathrm{H}_{3} \mathrm{O}_{2}{ }^{-} / \mathrm{SO}_{4}{ }^{-2}$ binary mixture from MDEA solutions (20-45 wt. \%) by the NF membrane is presented in Fig. 4(a-b). The pressure did not have a significant effect on the rejection rate

Table 2. Zeta potential of the NF-3 membrane versus $\mathrm{pH}$ value.

\begin{tabular}{cccccccccc}
\hline pH & $\mathbf{2 . 5}$ & $\mathbf{3 . 4 7}$ & $\mathbf{4 . 3 6}$ & $\mathbf{5 . 0 6}$ & $\mathbf{6 . 0 5}$ & $\mathbf{7 . 2}$ & $\mathbf{8 . 4 4}$ & $\mathbf{9 . 3 5}$ & $\mathbf{1 0 . 2}$ \\
\hline Zeta potential $(\mathrm{mV})$ & 31.6 & 23.5 & 11.5 & 0 & -21.5 & -45.6 & -62.4 & -69.4 & -73.3 \\
\hline
\end{tabular}




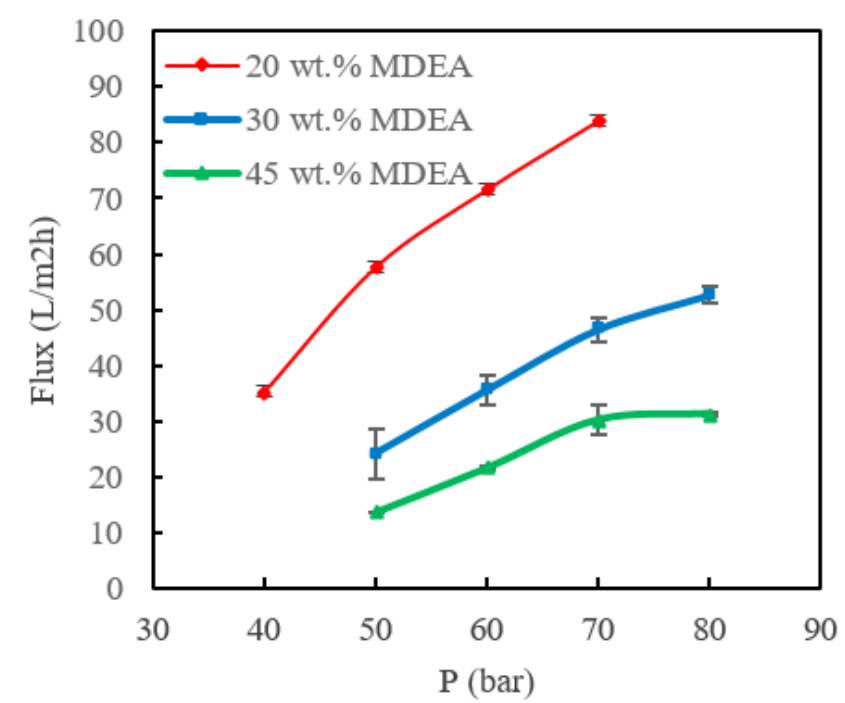

Figure 2. Influence of applied pressure on the permeate flux for different concentrations of MDEA (Feed flow rate: $0.693 \mathrm{~L} / \mathrm{h}$, Temperature: $35^{\circ} \mathrm{C}, \mathrm{pH}: 10$ ).

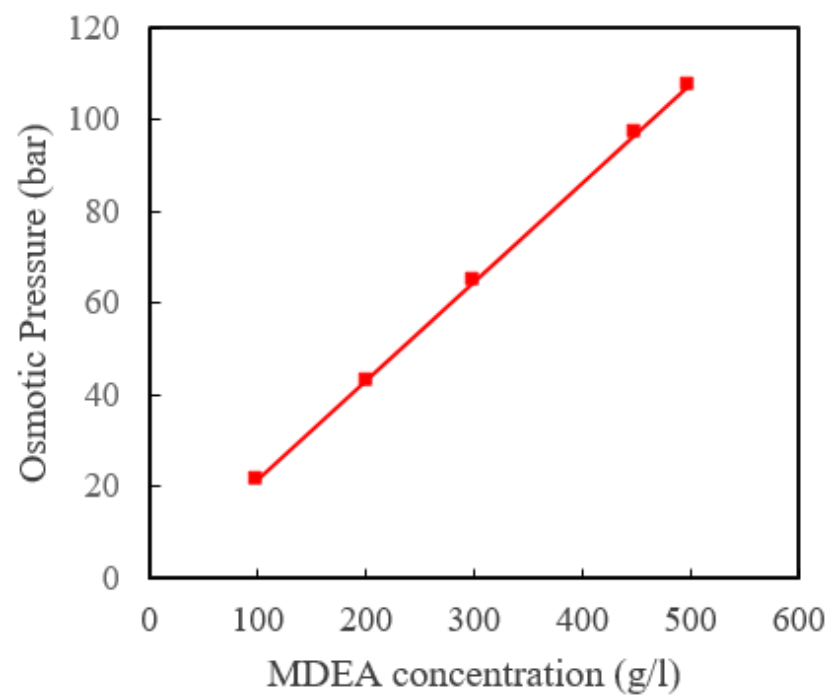

Figure 3. Osmotic pressure versus concentration of MDEA solution obtained from the Van't Hoff equation.

of sulfate and acetate ions from 20 and 30\% MDEA solutions, but for 45 wt. \% solutions of MDEA, increasing pressure slightly increased the rejection rate. The rejection of sulfate ions from 82.34 to $94.46 \%$ and the rejection of acetate ions from 31.8 to $40.92 \%$ for 45 wt. \% MDEA increased with increasing pressure from 50 to 80 bar. With increasing pressure, ion flux and water-MDEA flux are uncoupled, and convection becomes the dominant mechanism. Increasing operating pressure lead to a higher increment of solvent flux than ion flux due to the solution-diffusion mechanism (Gaikwad and Balomajumder, 2017a; Wu et al., 2015). Therefore, the concentration difference between the bulk and the surface layer of the feed increased with increasing pressure and led to an increase in the rejection rate (Dixon et al., 2011). On the other hand, although, according to Eq. (1), the linear variation of the solvent flux with increasing pressure specifies that the concentration polarization is negligible; the nonlinear variations in flux versus pressure in Fig. 2 shows the concentration polarization on the membrane side. Thus, the combination of both the convective mechanism and concentration polarization caused an insignificant rejection of ions by the membrane with increasing pressure (Fig. 4(ab)).

Fig. 4 shows that the rejection of sulfate and acetate ions decreased with increasing MDEA concentration from 20 to $45 \mathrm{wt}$. \%. This can be due to the solvent flux decrease and an increase in the flux of ions with
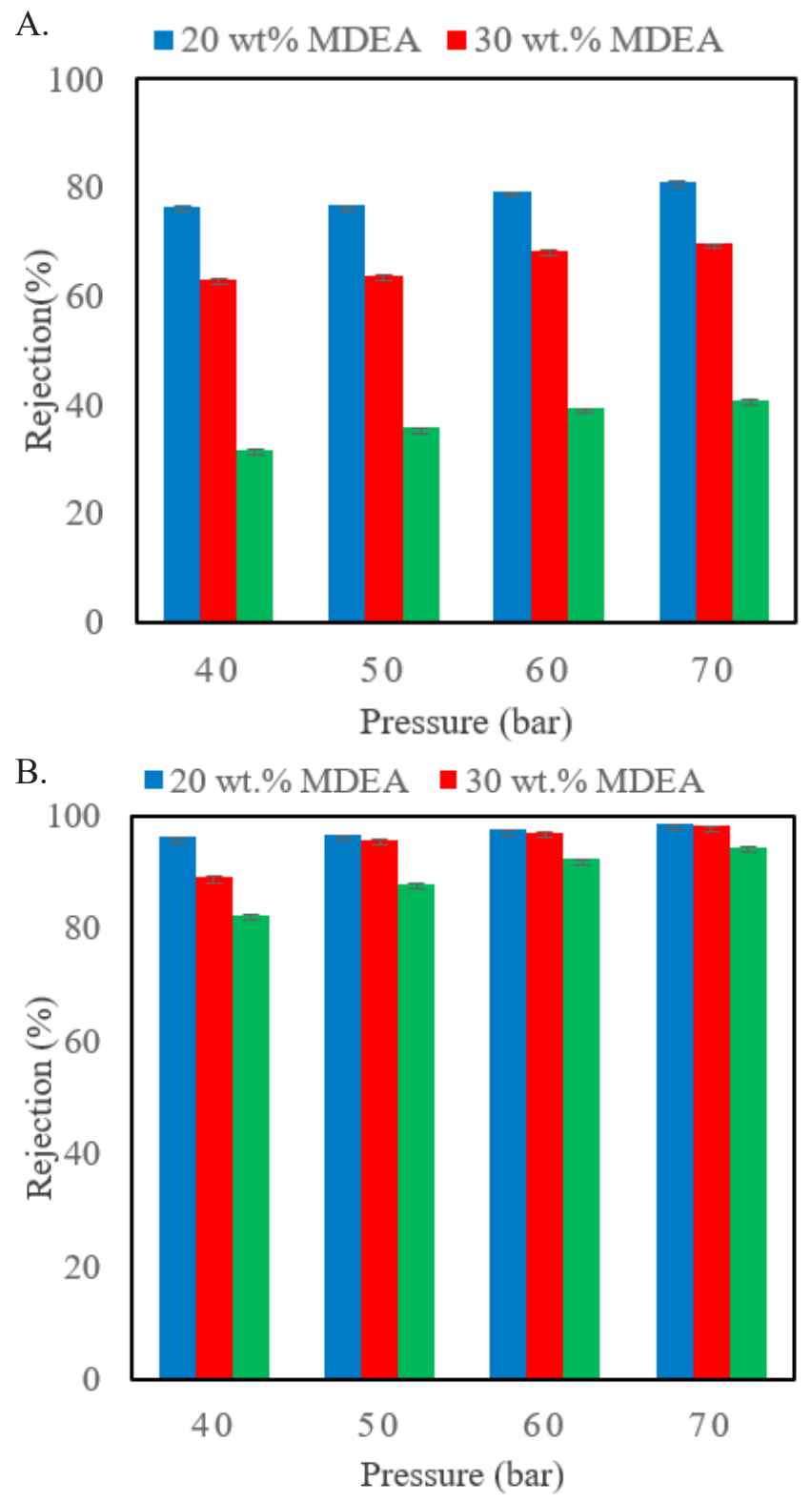

Figure 4. Influence of pressure on the rejection of a: acetate and $b$ : sulfate at different concentrations of MDEA (Feed flow rate: $0.693 \mathrm{~L} / \mathrm{h}$, Temperature: $35^{\circ} \mathrm{C}$, $\mathrm{pH}: 10)$. 
increasing MDEA concentration. Also, the rejection of divalent sulfate ions was higher than monovalent acetate ions at all amine concentrations. This can be due to the larger hydration radius and hydration energy of sulfate ions (Table 1). The higher hydration energy of ions provides a higher rejection of ions(Kelewou et al., 2011).

\section{Estimation of transport parameters}

As the transport parameters of ions in amine are unknown, the SKK model was used to predict the membrane parameters. The $\mathrm{P}_{\mathrm{S}}$ and $\sigma$ transport parameters were calculated by fitting the experimental data with the nonlinear Eq. (5). For this purpose, $R_{O}$ was plotted as a function of $\mathrm{J}_{\mathrm{V}}$. The $\mathrm{P}_{\mathrm{S}}$ and $\sigma$ values for acetate and sulfate ions were estimated in 20-45 wt. \% of MDEA solution, and are presented in Table 3. The results showed that the reflection coefficient of sulfate ions $(\sigma=0.99)$ was higher than acetate ions at all the concentrations of MDEA. The results revealed that the transfer of acetate ions was carried out simultaneously by two mechanisms of diffusion and convection, whereas the transfer of sulfate ions occurred mainly by the convection mechanism. According to Eqs. (3) and (4), the ion rejection increases with increasing solvent flux and, at an infinitely high solvent flux, the reflection coefficient reaches a limiting value. The diffusive transport of ions can be neglected in the higher solvent flux, and the reflection coefficient indicates a characteristic of the convective transport of ions. Therefore, the convection mass transfer is a dominant mechanism for the $\sigma$ value of $100 \%$ (Kelewou et al., 2011). Also the reflection coefficient is a characteristic of the rejection ability of ions through the membrane. Therefore, a higher $\sigma$ for sulfate ions can be due to their higher hydration energy. On the other hand, the reflection coefficient of acetate ions decreased from 0.8 to 0.43 with increasing MDEA concentration from 20 to $45 \mathrm{wt}$. \%, which can be due to increased transfer of ions across the NF membrane with increasing MDEA concentration. Also, the solute permeability $\left(\mathrm{P}_{\mathrm{S}}\right)$ for acetate was higher than sulfate due to the higher rejection of sulfate ions. On the other hand, permeability increases with increasing MDEA concentration due to increased ion transfer through the membrane with increasing MDEA concentration.

The solvent permeability was estimated with Eq. (1) by fitting the plot of permeate flux versus $(\Delta \mathrm{P}-$ $\sigma \Delta \pi)$ (Fig. 5). The results obtained are presented in Table 3 . As can be seen, the solvent permeability was reduced with increasing concentration of amine in the feed solution from 1.53 to $0.62 \mathrm{~L} / \mathrm{h} \cdot \mathrm{m}^{2}$, due to the osmotic pressure increase with MDEA concentration, thereby reducing solvent flux.

Finally, the rejection rates of the SKK model were calculated using Eq. (5) and $\sigma$ and $\mathrm{P}_{\mathrm{S}}$ obtained (Table
Table 3. The $\sigma, \mathrm{P}_{\mathrm{s}}$ and $\mathrm{L}_{\mathrm{p}}$ parameters obtained from the SKK model at different concentrations of MDEA.

\begin{tabular}{cccccc}
\hline $\begin{array}{c}\text { MDEA } \\
\text { conc. }\end{array}$ & \multicolumn{2}{c}{ Acetate } & \multicolumn{2}{c}{ Sulfate } & \multirow{2}{*}{$\mathbf{L}_{\mathbf{P}}$} \\
\cline { 2 - 5 } (wt. \%) & $\sigma$ & $\begin{array}{c}\mathbf{P}_{\mathbf{S}} \\
\left(\mathbf{L} / \mathbf{h} \cdot \mathbf{m}^{2}\right)\end{array}$ & $\sigma$ & $\begin{array}{c}\mathbf{P}_{\mathbf{S}} \\
\left(\mathbf{L} / \mathbf{h} \cdot \mathbf{m}^{2}\right)\end{array}$ & $\left(\mathbf{L} / \mathbf{h} \cdot \mathbf{m}^{\mathbf{2}}\right)$ \\
\hline 20 & 0.80 & 5.29 & 0.99 & 1.01 & 1.53 \\
30 & 0.72 & 6.85 & 0.99 & 1.29 & 0.96 \\
45 & 0.43 & 8.78 & 0.99 & 2.27 & 0.62 \\
\hline
\end{tabular}

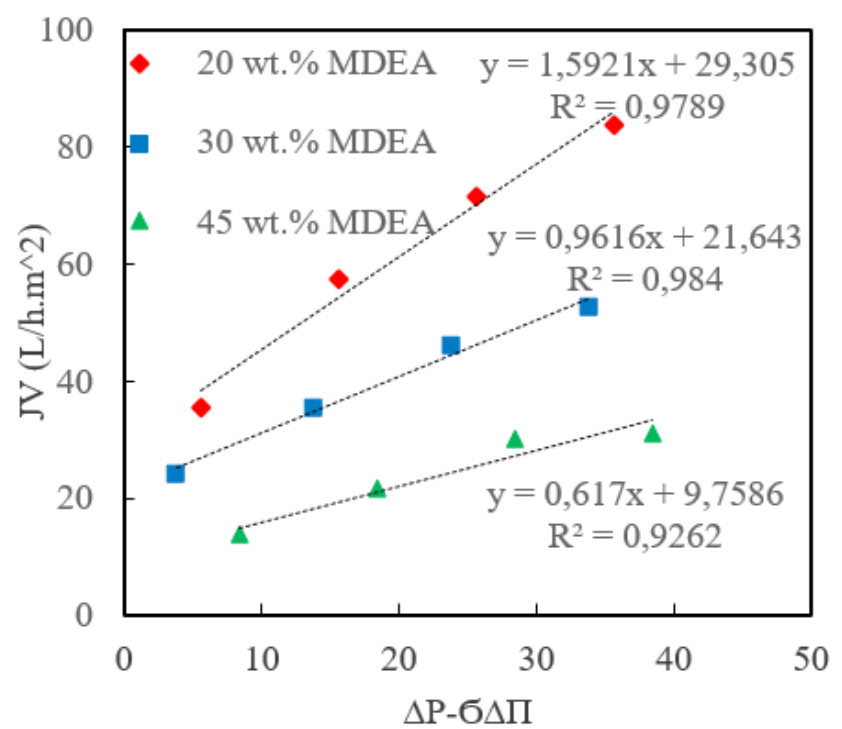

Figure 5. Fitting of solvent permeability for different concentrations of MDEA.

3). Acceptable agreement (correlation) between model results and experimental data can be seen in Fig. 6. This model show errors less than $1 \%\left(>\mathrm{R}^{2}=0.98\right)$ and $3 \%$ $\left(>\mathrm{R}^{2}=0.75\right)$ for sulfate and acetate ions, respectively.

Since in the SKK model the charge of ions and membrane is not taken into account,.Garba et al. (1999) presented a model according to the film theory and the extended Nernst-Planck equations. The model is presented as the following equation:

$\ln \left(1-\mathrm{R}_{\mathrm{O}}\right)=-\frac{1}{\mathrm{~K}_{\mathrm{eff}}} \mathrm{J}_{\mathrm{V}}+\ln \Phi$

This model computes the transport parameters, including the ion transmittance $(\Phi)$, and the effective ion transfer coefficient $\left(\mathrm{K}_{\text {eff }}\right)$. The model parameters were estimated by plotting $\ln \left(1-\mathrm{R}_{\mathrm{O}}\right)$ versus $\mathrm{J}_{\mathrm{V}}$. The fitted plot is presented in Fig. 7 and the calculated parameters values are given in Table 4. With increasing MDEA concentration in the feed solution, the effective transfer coefficients $\left(\mathrm{K}_{\text {eff }}\right)$ of sulfate and acetate ions were reduced from 56.15 to 16.68 $\mathrm{L} / \mathrm{m}^{2} \mathrm{~h}$ and from 223.1 to $130.4 \mathrm{~L} / \mathrm{m}^{2} \mathrm{~h}$, respectively, but the ion transmittance $(\Phi)$ of sulfate and acetate ions increased from $8.15 \%$ to $41.59 \%$ and $28.43 \%$ to $75.78 \%$, respectively. The percentage of ions passing through the NF membrane is strongly dependent on 

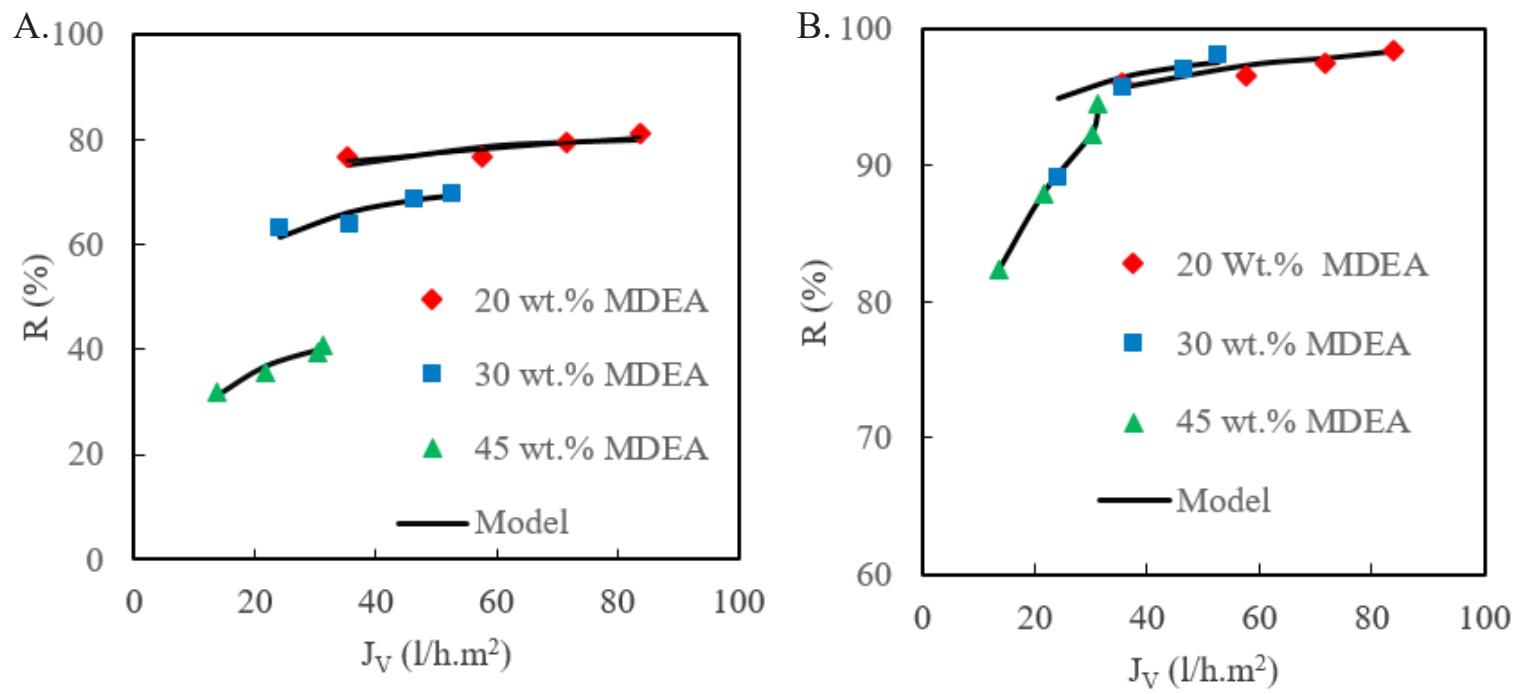

Figure 6. Theoretical and experimental rejection for a: acetate and b: sulfate at different concentrations of MDEA.

the ion transmittance $(\Phi)$, especially when the solvent flux is near zero (Garba et al., 2003). Therefore, the solvent flux decreases with an increment in the MDEA concentration and the transfer of ions through the membrane increases due to increasing diffusion transport. Thus, the ion transmittance $(\Phi)$ increases, and the effective transfer coefficient $\left(\mathrm{K}_{\text {eff }}\right)$ decreases with enhancement of the MDEA concentration. Also, sulfate ions were more rejected than acetate ions due to their divalent charge and higher hydration energy (Table 1). Therefore, sulfate ions have lower $\mathrm{K}_{\text {eff }}$ and $\Phi$ than acetate ions.

In order to compare the experimental data and the model, the rejection rate was calculated using the model parameters (Table 4) and Eq. (9), and are presented in Fig. 8. As can be seen in Fig. 8, the proposed model of the film theory and the extended Nernst-Planck equations agree better than the SKK model for sulfate ions, which can be due to considering the divalent

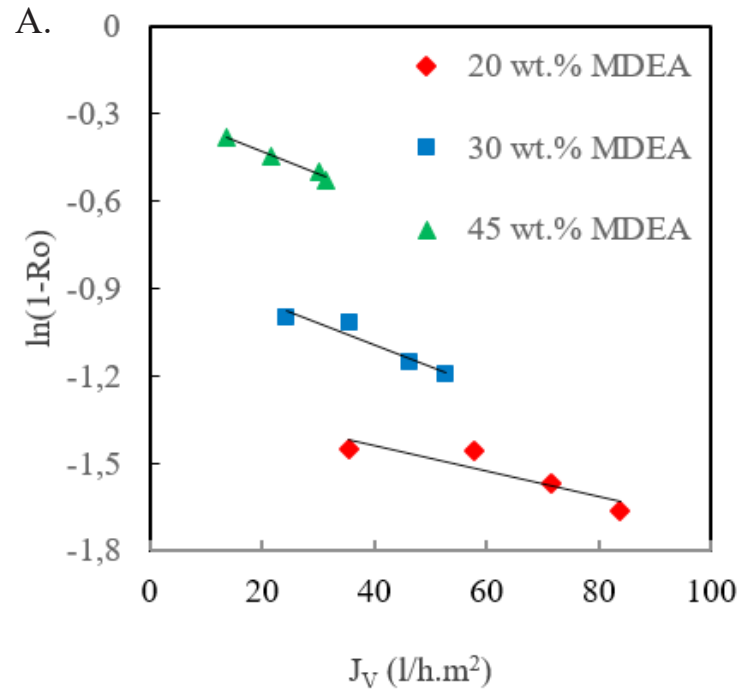

Table 4. Transport parameters $\mathrm{K}_{\text {eff }}$ and $\Phi$ obtained from the model for acetate and sulfate at different concentrations of MDEA.

\begin{tabular}{ccccc}
\hline \multirow{2}{*}{$\begin{array}{c}\text { MDEA } \\
\text { conc. } \\
\text { (wt. } \%)\end{array}$} & \multicolumn{2}{c}{ Acetate } & \multicolumn{2}{c}{ Sulfate } \\
\cline { 2 - 5 } & $\begin{array}{c}\mathbf{K}_{\text {eff }} \\
\left(\mathbf{L} / \mathbf{h}_{\mathbf{m}} \mathbf{m}^{\mathbf{2}}\right)\end{array}$ & $\mathbf{\%} \boldsymbol{\Phi}$ & $\begin{array}{c}\mathbf{K}_{\text {eff }} \\
\left(\mathbf{L} / \mathbf{h} . \mathbf{m}^{\mathbf{2}}\right)\end{array}$ & $\mathbf{\% \Phi}$ \\
\hline 20 & 223.1 & 28.43 & 56.15 & 8.15 \\
30 & 134.0 & 45.19 & 17.10 & 41.11 \\
45 & 130.4 & 75.78 & 16.68 & 41.59 \\
\hline
\end{tabular}

charge of sulfate ions in the model. The FT-ENP model show errors less than $1 \%\left(>R^{2}=0.98\right)$ and $2 \%$ $\left(>R^{2}=0.89\right)$ for sulfate and acetate ions, respectively.

The accuracy of the model can also be estimated by determination of the R-squared and adjusted $\mathrm{R}$-squared. The $\mathrm{R}^{2}$ and $\mathrm{R}^{2}$ adj measure the variability in the response values and the fraction of variation of the response explained by the model adjusted for degrees of freedom, respectively.

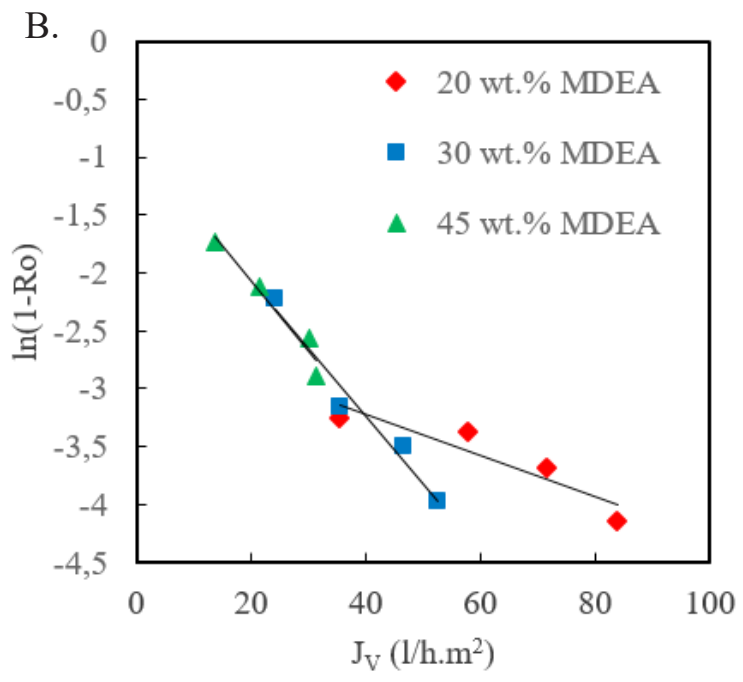

Figure 7. Estimate of model parameters from the $\ln \left(1-\mathrm{R}_{\mathrm{O}}\right)$ versus $\mathrm{J}_{\mathrm{v}}$ curve for $\mathrm{a}$ : acetate and $\mathrm{b}$ : sulfate at different concentrations of MDEA. 

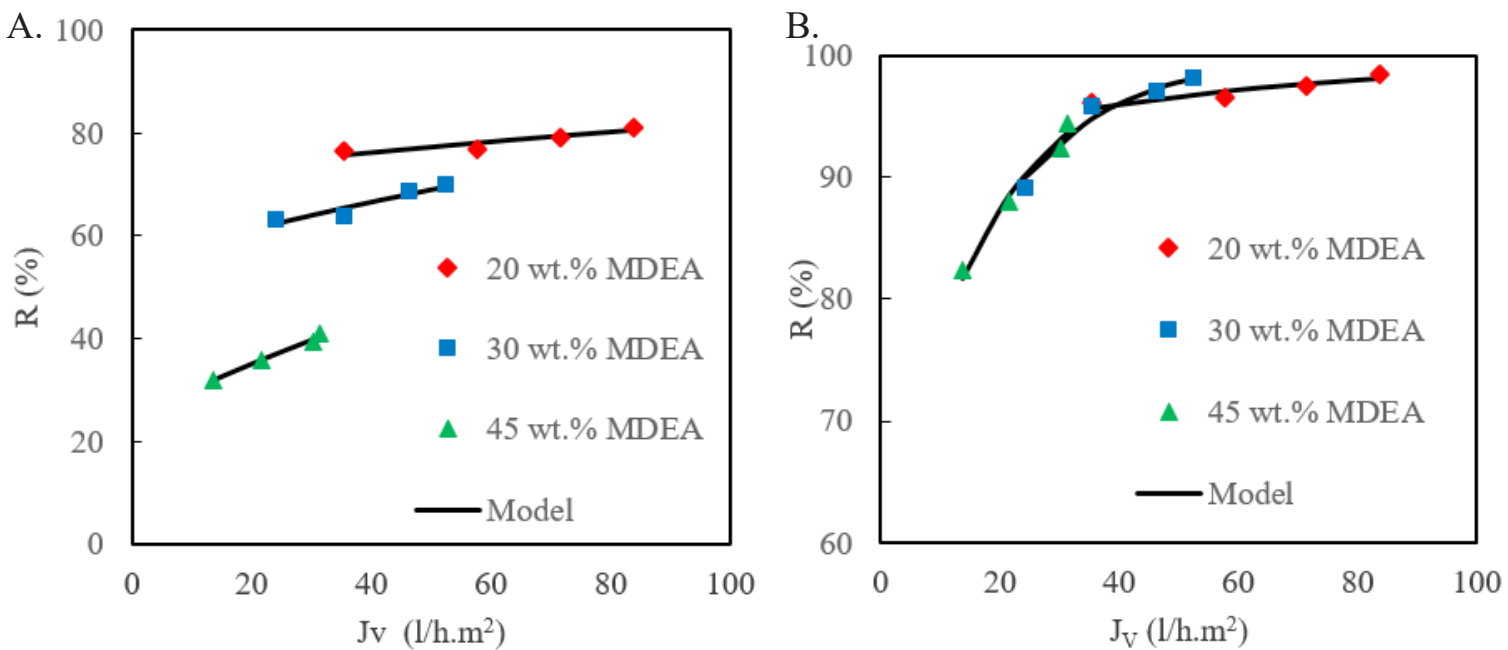

Figure 8. Theoretical and experimental rejection for $a$ : acetate and $b$ : sulfate at different concentrations of MDEA.

Generally, the results evidence that both the SKK model and FT-ENP model could be useful and practical models for predicting the ion rejection of the amine solutions by the NF membrane, as well as examining the transport parameters of ions.

\section{CONCLUSION}

In this work, rejection of the binary mixture of acetate and sulfate ions and permeate flux, at different concentrations of MDEA solution (20-45 wt. \%), were studied by using commercial NF-3 nanofiltration membrane in a variety of operating pressures (40-80 bar). The results showed that the permeate flux increased for all of the MDEA concentration range with increasing pressure. However, with increasing concentration of MDEA, from 20 to $45 \mathrm{wt}$. \%, the permeate flux reduced due to increased osmotic pressure. The results of ion rejection showed that the increase in pressure has an insignificant effect on the rejection of acetate and sulfate ions for MDEA solutions of 20 and 30 wt. \%, which could be due to convective transfer and concentration polarization within the membrane. However, for 45 wt. \% solutions of MDEA, the rejection rate slightly increased with increasing pressure. At a MDEA concentration of $20 \%$ wt. and pressure of $70 \mathrm{bar}$, the maximum rejections of $80 \%$ and $98 \%$ were obtained for acetate and sulfate, respectively.

The performance of the NF membrane in the removal of HSS ions from the MDEA solution was investigated by the transport parameters $\left(\sigma, P_{S}\right.$ and $\mathrm{L}_{\mathrm{P}}$ ) of the SKK model through experimental data. The reflection coefficient for acetate ions decreased with increasing MDEA concentration due to reducing the rejection rate, while the reflection coefficient $(\sigma=0.99)$ of sulfate ions remained constant with increasing MDEA concentration due to the high rejection of sulfate ions. Since the SKK model does not consider the charge of ions and membranes, the
FT-ENP equation was also used to calculate transport parameters $\left(\mathrm{K}_{\mathrm{eff}}\right.$ and $\left.\Phi\right)$ and to predict rejection. The rejection rates were calculated from the transport parameters and the two models compared with the experimental data. A satisfactory agreement between the calculated and experimental rejection curves was observed for the two models. For sulfate ions, the FTENP model has a better agreement (with error less than $1 \%$ and $>\mathrm{R}^{2}=0.98$ ) due to consideration of the repulsion between the divalent charge of sulfate ions and the membrane.

\section{ACKNOWLEDGMENTS}

The authors wish to thank Ilam University for the financial support of this work. Also, thank co-workers and technical staff in the chemical engineering department.

\section{REFERENCES}

Anisah, S., Kanezashi, M., Nagasawa, H., Tsuru, T. Hydrothermal stability and permeation properties of $\mathrm{TiO} 2-\mathrm{ZrO} 2(5 / 5)$ nanofiltration membranes at high temperatures. Separation and Purification Technology, 212, 1001-1012 (2019). https://doi. org/10.1016/j.seppur.2018.12.006

Bazhenov, S., Rieder, A., Schallert, B., Vasilevsky, V., Unterberger, S., Grushevenko, E., Volkov, V., Volkov, A. Reclaiming of degraded MEA solutions by electrodialysis: Results of ED pilot campaign at post-combustion $\mathrm{CO}_{2}$ capture pilot plant. International Journal of Greenhouse Gas Control, 42, 593-601 (2015). https://doi.org/10.1016/j. ijggc.2015.09.015

Cho, J.-H., Jeon, S.-B., Yang, K.-S., Seo, J.-B., Cho, S.-W., Oh, K.-J., Regeneration of heat stable saltsloaded anion exchange resin by a novel zirconium pentahydroxide $\quad\left[\mathrm{Zr}(\mathrm{OH}) 5^{-}\right]$displacement 
technique in $\mathrm{CO}_{2}$ absorption process. Separation and Purification Technology, 156, 465-471 (2015). https://doi.org/10.1016/j.seppur.2015.10.036

Déon, S., Escoda, A., Fievet, P., Dutournié, P., Bourseau, P. How to use a multi-ionic transport model to fully predict rejection of mineral salts by nanofiltration membranes. Chemical Engineering Journal, 189-190, 24-31 (2012). https://doi. org/10.1016/j.cej.2012.02.014

Diawara, C. K., Lô, S. M., Rumeau, M., Pontie, M., Sarr, O. A phenomenological mass transfer approach in nanofiltration of halide ions for a selective defluorination of brackish drinking water. Journal of Membrane Science, 219, 103-112 (2003). https://doi.org/10.1016/S0376-7388(03)00189-3

Dixon, M. B., Falconet, C., Ho, L., Chow, C. W. K., O'Neill, B. K., Newcombe, G. Removal of cyanobacterial metabolites by nanofiltration from two treated waters. Journal of Hazardous Materials, 188, 288-295 (2011). https://doi.org/10.1016/j. jhazmat.2011.01.111

Dumée, L., Scholes, C., Stevens, G., Kentish, S. Purification of aqueous amine solvents used in post combustion $\mathrm{CO}_{2}$ capture: A review. International Journal of Greenhouse Gas Control, 10, 443-455 (2012). https://doi.org/10.1016/j.ijggc.2012.07.005

Epsztein, R., Cheng, W., Shaulsky, E., Dizge, N., Elimelech, M. Elucidating the mechanisms underlying the difference between chloride and nitrate rejection in nanofiltration. Journal of Membrane Science, 548, 694-701 (2018). https:// doi.org/10.1016/j.memsci.2017.10.049

Fang, J., Deng, B. Rejection and modeling of arsenate by nanofiltration: Contributions of convection, diffusion and electromigration to arsenic transport. Journal of Membrane Science, 453, 42-51 (2014). https://doi.org/10.1016/j.memsci.2013.10.056

Fridman-Bishop, N., Tankus, K. A., Freger, V. Permeation mechanism and interplay between ions in nanofiltration. Journal of Membrane Science, 548, 449-458 (2018). https://doi.org/10.1016/j. memsci.2017.11.050

Gaikwad, M. S., Balomajumder, C. Simultaneous rejection of chromium(VI) and fluoride [Cr(VI) and F] by nanofiltration: Membranes characterizations and estimations of membrane transport parameters by CFSK model. Journal of Environmental Chemical Engineering, 5, 45-53 (2017a). https:// doi.org/10.1016/j.jece.2016.11.018

Gaikwad, M. S., Balomajumder, C. Simultaneous rejection of fluoride and $\mathrm{Cr}(\mathrm{VI})$ from synthetic fluoride-Cr(VI) binary water system by polyamide flat sheet reverse osmosis membrane and prediction of membrane performance by CFSK and CFSD models. Journal of Molecular Liquids, 234, 194-200 (2017b). https://doi.org/10.1016/j. molliq.2017.03.073
Gaikwad, M. S., Balomajumder, C. TFC polyamide $\mathrm{NF}$ membrane: characterization, application and evaluation of MTPs and MTC for simultaneous removal of hexavalent chromium and fluoride. e-Polymers, 17, 129-136 (2017c). https://doi. org/10.1515/epoly-2016-0219

Gao, J., Wang, S., Wang, J., Cao, L., Tang, S., Xia, Y. Effect of $\mathrm{SO}_{2}$ on the amine-based $\mathrm{CO}_{2}$ capture solvent and improvement using ion exchange resins. International Journal of Greenhouse Gas Control, 37, 38-45 (2015). https://doi.org/10.1016/j. ijggc.2015.03.001

Garba, Y., Taha, S., Cabon, J., Dorange, G. Modeling of cadmium salts rejection through a nanofiltration membrane: relationships between solute concentration and transport parameters. Journal of Membrane Science, 211, 51-58 (2003). https://doi. org/10.1016/S0376-7388(02)00328-9

Garba, Y., Taha, S., Gondrexon, N., Dorange, G., Ion transport modelling through nanofiltration membranes. Journal of Membrane Science, 160, 187-200 (1999). https://doi.org/10.1016/S03767388(99)00085-X

Hidalgo, A. M., León, G., Gómez, M., Murcia, M. D., Gómez, E., Gómez, J.L., Application of the Spiegler-Kedem-Kachalsky model to the removal of 4-chlorophenol by different nanofiltration membranes. Desalination, 315, 70-75 (2013). https://doi.org/10.1016/j.desal.2012.10.008

$\mathrm{Hu}, \mathrm{K}$., Dickson, J. M. Nanofiltration membrane performance on fluoride removal from water. Journal of Membrane Science, 279, 529-538 (2006). https://doi.org/10.1016/j.memsci.2005.12.047

Jaafari, L., Jaffary, B., Idem, R. Screening study for selecting new activators for activating MDEA for natural gas sweetening. Separation and Purification Technology, 199, 320-330 (2018). https://doi. org/10.1016/j.seppur.2018.02.007

Keewan, M., Banat, F., Alhseinat, E., Zain, J., Pal, P. Effect of operating parameters and corrosion inhibitors on foaming behavior of aqueous methyldiethanolamine solutions. Journal of Petroleum Science and Engineering, 165, 358-364 (2018). https://doi.org/10.1016/j. petrol.2018.02.046

Kelewou, H., Lhassani, A., Merzouki, M., Drogui, P., Sellamuthu, B. Salts retention by nanofiltration membranes: Physicochemical and hydrodynamic approaches and modeling. Desalination, 277, 106-112 (2011). https://doi.org/10.1016/j. desal.2011.04.010

Lim, J., Scholes, C. A., Dumée, L. F., Kentish, S. E. Nanofiltration for the concentration of heat stable salts prior to MEA reclamation. International Journal of Greenhouse Gas Control, 30, 34-41 (2014). https://doi.org/10.1016/j.ijggc.2014.08.020 
Lu, H. T., Kanehashi, S., Scholes, C. A., Kentish, S. E. The impact of ethylene glycol and hydrogen sulphide on the performance of cellulose triacetate membranes in natural gas sweetening. Journal of Membrane Science, 539, 432-440 (2017). https:// doi.org/10.1016/j.memsci.2017.06.023

Marchetti, P., Jimenez Solomon, M. F., Szekely, G., Livingston, A. G. Molecular Separation with Organic Solvent Nanofiltration: A Critical Review. Chemical Reviews, 114, 10735-10806 (2014). https://doi.org/10.1021/cr500006j

Meng, H., Zhang, S., Li, C., Li, L. Removal of heat stable salts from aqueous solutions of $\mathrm{N}$-methyldiethanolamine using a specially designed three-compartment configuration electrodialyzer. Journal of Membrane Science, 322, 436-440 (2008). https://doi.org/10.1016/j.memsci.2008.05.072

Najibi, H., Maleki, N. Equilibrium solubility of carbon dioxide in N-methyldiethanolamine+piperazine aqueous solution: Experimental measurement and prediction. Fluid Phase Equilibria, 354, 298-303 (2013). https://doi.org/10.1016/j.fluid.2013.06.022

Nakari, O., Pihlajamäki, A., Mänttäri, M. Permeability of dilute ionic liquid solutions through a nanofiltration membrane - Effect of ionic liquid concentration, filtration pressure and temperature. Separation and Purification Technology, 163, 267-274 (2016). https://doi.org/10.1016/j. seppur.2016.02.052

Pal, P., AbuKashabeh, A., Al-Asheh, S., Banat, F., Accumulation of heat stable salts and degraded products during thermal degradation of aqueous methyldiethanolamine (MDEA) using microwave digester and high pressure reactor. Journal of Natural Gas Science and Engineering, 21, 1043-1047 (2014). https://doi.org/10.1016/j. jngse.2014.11.007

Pal, P., AbuKashabeh, A., Al-Asheh, S., Banat, F. Role of aqueous methyldiethanolamine (MDEA) as solvent in natural gas sweetening unit and process contaminants with probable reaction pathway. Journal of Natural Gas Science and Engineering, 24, 124-131 (2015). https://doi.org/10.1016/j. jngse.2015.03.007

Pal, P., Banat, F., AlShoaibi, A. Adsorptive removal of heat stable salt anions from industrial lean amine solvent using anion exchange resins from gas sweetening unit. Journal of Natural Gas Science and Engineering, 15, 14-21 (2013). https://doi. org/10.1016/j.jngse.2013.08.001

Pérez, L., Escudero, I., Arcos-Martínez, M. J., Benito, J. M. Application of the solution-diffusion-film model for the transfer of electrolytes and uncharged compounds in a nanofiltration membrane. Journal of Industrial and Engineering Chemistry, 47, 368-374 (2017). https://doi.org/10.1016/j.jiec.2016.12.007
Poormohammadian, S. J., Lashanizadegan, A., Salooki, M. K. Modelling VLE data of $\mathrm{CO}_{2}$ and $\mathrm{H}_{2} \mathrm{~S}$ in aqueous solutions of $\mathrm{N}$-methyldiethanolamine based on non-random mixing rules. International Journal of Greenhouse Gas Control, 42, 87-97 (2015). https://doi.org/10.1016/j.ijggc.2015.07.036

Qeshta, H. J., Abuyahya, S., Pal, P., Banat, F. Sweetening liquefied petroleum gas (LPG): Parametric sensitivity analysis using Aspen HYSYS. Journal of Natural Gas Science and Engineering, 26, 1011-1017 (2015). https://doi. org/10.1016/j.jngse.2015.08.004

Qiu, K., Shang, J. F., Ozturk, M., Li, T. F., Chen, S. K., Zhang, L. Y., Gu, X. H. Studies of methyldiethanolamine process simulation and parameters optimization for high-sulfur gas sweetening. Journal of Natural Gas Science and Engineering, 21, 379-385 (2014). https://doi. org/10.1016/j.jngse.2014.08.023

Rebolledo-Libreros, M. A. E., Trejo, A. Gas solubility of $\mathrm{CO}_{2}$ in aqueous solutions of $\mathrm{N}$-methyldiethanolamine and diethanolamine with 2-amino-2-methyl-1-propanol. Fluid Phase Equilibria, 218, 261-267 (2004). https://doi. org/10.1016/j.fluid.2003.12.012

Roy, Y., Warsinger, D. M., Lienhard, J. H. Effect of temperature on ion transportin nanofiltration membranes: Diffusion, convection and electromigration. Desalination, 420, 241-257 (2017). https://doi.org/10.1016/j.desal.2017.07.020

Ryzhkov, I. I., Minakov, A. V. Theoretical study of electrolyte transport in nanofiltration membranes with constant surface potential/charge density. Journal of Membrane Science, 520, 515-528 (2016). https://doi.org/10.1016/j.memsci.2016.08.004

Saliha, B., Patrick, F., Anthony, S. Investigating nanofiltration of multi-ionic solutions using the steric, electric and dielectric exclusion model. Chemical Engineering Science, 64, 3789-3798 (2009). https://doi.org/10.1016/j.ces.2009.05.020

Santafé-Moros, A., Gozálvez-Zafrilla, J. M., Lora-García, J. Performance of commercial nanofiltration membranes in the removal of nitrate ions. Desalination, 185, 281-287 (2005). https:// doi.org/10.1016/j.desal.2005.02.080

Santaniello, A., Golemme, G. Interfacial control in perfluoropolymer mixed matrix membranes for natural gas sweetening. Journal of Industrial and Engineering Chemistry, 60, 169-176 (2018). https://doi.org/10.1016/j.jiec.2017.11.002

Verma, N., Verma, A. Amine system problems arising from heat stable salts and solutions to improve system performance. Fuel Processing Technology, 90, 483-489 (2009). https://doi.org/10.1016/j. fuproc.2009.02.002 
Wang, T., Hovland, J., Jens, K. J. Amine reclaiming technologies in post-combustion carbon dioxide capture. Journal of Environmental Sciences, 27, 276-289 (2015). https://doi.org/10.1016/j. jes.2014.06.037

Wei, C., He, Z., Lin, L., Cheng, Q., Huang, K., Ma, S., Chen, L. Negatively charged polyimide nanofiltration membranes with high selectivity and performance stability by optimization of synergistic imidization. Journal of Membrane Science, 563, 752-761 (2018). https://doi.org/10.1016/j. memsci.2018.06.046

Wei, X., Shi, Y., Fei, Y., Chen, J., Lv, B., Chen, Y., Zheng, H., Shen, J., Zhu, L. Removal of trace phthalate esters from water by thin-film composite nanofiltration hollow fiber membranes. Chemical Engineering Journal, 292, 382-388 (2016). https:// doi.org/10.1016/j.cej.2016.02.037

Wu, F., Feng, L., Zhang, L. Rejection prediction of isopropylantipyrine and antipyrine by nanofiltration membranes based on the SpieglerKedem-Katchalsky model. Desalination, 362, 11-17 (2015). https://doi.org/10.1016/j. desal.2015.01.046

Zhang, Y., Zhang, L., Hou, L., Kuang, S., Yu, A. Modeling of the variations of permeate flux, concentration polarization, and solute rejection in nanofiltration system. AIChE Journal, 65, 10761087 (2019). https://doi.org/10.1002/aic.16475

Zhao, C., Tang, C. Y., Li, P., Adrian, P., Hu, G. Perfluorooctane sulfonate removal by nanofiltration membrane - the effect and interaction of magnesium ion / humic acid. Journal of Membrane Science, 503, 31-41 (2016). https://doi.org/10.1016/j. memsci.2015.12.049

Zhao, C., Zhang, J., He, G., Wang, T., Hou, D., Luan, Z. Perfluorooctane sulfonate removal by nanofiltration membrane the role of calcium ions. Chemical Engineering Journal, 233, 224-232 (2013). https://doi.org/10.1016/j.cej.2013.08.027 
